\title{
Editorial
}

\section{Consumer empowerment in financial services: Rhetoric or reality?}

It is generally acknowledged that there has been a shift in power from the producer to the consumer. Indeed, the post-modern approach views the consumer as someone reversing the power in the marketing system. Hence, consumers are increasingly recognised as being active rather than passive (subversive even in some areas, for example GM foods). Trends in deregulation and competitive practices have facilitated the creation of more options to consumers, giving them greater choice and freedom to exert their preferences. At the same time, individuals themselves have become more pro-active in terms of acquiring knowledge, in turn increasing in sophistication as consumers of goods and services. The 'information explosion' has been acknowledged as a factor contributing to this shift in power, resulting in empowerment, voice and action.

While these trends are discernible at a general level, it is debatable to what extent the same cultural shifts in consumption are evident in the financial services sector. It is recognised that customer switching has increased, hence the preoccupation with customer retention, relationship management and loyalty strategies, but does this increased mobility really represent the actions and behaviour of empowered consumers? It might be argued that a vast proportion of financial services consumers remain inactive and/or indifferent to the services they receive and that consumer ignorance prevails as a result of financial services being complex and, in many cases, non-comparable.
Indeed, this is one of the reasons put forward for the active role of marketing (or rather 'sales') in helping to construct consumer 'needs', contrasting sharply with the notion of an active and sovereign consumer. In order to be an active and empowered consumer, individuals need to have access to the necessary information to make an informed decision, and also be in a position to understand and evaluate the information.

These issues have resulted in information provision and consumer education being a subject of public policy. The Financial Services Authority (FSA), the UK's financial regulator, has a statutory objective, under the Financial Services and Markets Act 2000, to promote public understanding of the financial system. In this context, the FSA has two key roles: to enhance financial literacy, and to provide generic advice, thus, affording greater protection to the consumer. In addition, the FSA's proposals to liberalise the socalled 'polarisation' regime that currently governs the way in which financial advice is structured in the UK is expected to offer consumers greater choice and access to professional financial advice services. Such proposals are likely to be based on the recognition that there are individual and systemic implications when the provision of information and advice is inadequate, such as: the mis-selling of products, the mis-buying of products and marketplace dysfunction. Uninformed consumers are vulnerable to exploitation and may make inefficient or even harmful choices. Moreover, efficient information provision 
is necessary to maintain the competitiveness of markets through the actions of knowledgeable and demanding consumers.

There is a need to gain a better understanding of the respective roles of information and advice in consumer decision making in order to assess the extent to which it is possible to enhance consumer knowledge and understanding and, in turn, consumer empowerment.

Information and advice are distinct yet related concepts. Information can be defined as 'relevant data' that may be presented verbally, pictorially or in written form and which may originate from marketing sources, personal sources or neutral sources. Advice, on the other hand, is information shaped to the needs of the individual. Whereas an information giver has a passive role (ie merely handing over relevant leaflets or giving a general explanation), an adviser actively interprets information, offers opinions and probes beyond the immediate problem. Thus, an adviser exercises judgment about the capacity of the inquirer, the priority of needs and the way that services and facilities should be approached.

The activity of information gathering is a key stage in the consumer decisionmaking process: consumers use information to decide whether to purchase or re-purchase a product or service. In conventional models of consumer behaviour, information is recognised as originating from either internal or external sources. Since financial services are often infrequent purchases, the extent to which consumers can draw on internal sources of information (such as familiarity, accumulated knowledge and past experience) is likely to be limited. Thus, external sources of information are likely to be valuable in addressing the knowledge and experience gaps.

While information is important, acquiring it involves a certain amount of cost to the consumer. Consequently, it is generally understood that the consumer will not continue to search for information once its value becomes smaller than the cost involved in obtaining it. The extent of information search is also affected by a number of factors particular to the market environment, situational variables, product importance, knowledge and experience of the buyer as well as a whole host of individual differences. Research into these factors has revealed at times inconclusive and contradictory findings. For example some research has shown that high numbers of product alternatives and high levels of product complexity will lead to limited (rather than extended) search activity simply because the 'cost of thinking' increases. Other research has shown that high levels of product familiarity and knowledge actually increase (rather than decrease) external information-seeking behaviour. The explanation is that more knowledgeable consumers are better equipped to gather and make sense of information than less knowledgeable consumers, and that a certain base level of knowledge is required for information search to be productive.

The extent of search activity is also related to type of product, with important implications for financial services. For example financial services are commonly viewed as high in experience and credence factors, due to their characteristics of intangibility and degree of customisation. Coupled with the financial significance of many financial services and the impact on the financial welfare of the consumer, it is not surprising that decision making in this context tends to be complex with higher perceptions of risk. These factors are thought to lead to extended search behaviour. Yet, experience qualities increase the search costs since in order to acquire information on experience qualities purchase and consumption must take place. While in theory consumers might 
be expected to gather information from a wide variety of sources before making purchase decisions, in practice information search appears to be restricted or inhibited. This arises when consumers lack the knowledge to make sense of information or because the information simply is not available because institutions' offerings are incomparable. This asymmetry of information can place the consumer in a vulnerable position.

This is one of the key factors that make financial advice attractive to consumers. Financial 'know-how' is a critical factor in the purchase of financial products and where consumers do not have and do not wish to develop this 'know-how' they may seek advice. Taking advice is a central component of realistic decision making, since decision problems rarely present themselves with the relevant information as given. This is just as true for purchase decisions as for any other decision-making situation. Thus, decision makers may engage in interactive processes in order to build the relevant informational basis. In the context of purchasing financial services, this means making use of professional financial advice (whether it is in the form of independent advice or not).

A recent survey commissioned by the Financial Services Authority (see 'Polarisation: Consumer Research', January 2002) found that around one adult in every five has recently sought financial advice from a bank, building society or insurance company; one in eight has recently used an independent financial adviser. The majority of people using an adviser tend to consult only one, and the proportion of people using an adviser tends to increase with income. The main reasons for using an adviser are: lack of knowledge about financial services in general; lack of up-to-date knowledge; or the need for guidance in specialist areas (such as pensions and tax). Some consumers make their own decisions, but seek reassurance from an adviser that the right decision is being taken. A small proportion of financially sophisticated consumers make their own decisions, but use advisers for convenience.

The choice of an adviser is a decision in itself. Moreover, the findings of the FSA report would seem to suggest the possibility that some consumers are delegating the responsibility of their own financial decisions to a third party with little thought or understanding as to the nature of advice the professional is legally obliged to provide. Financially sophisticated consumers are generally aware of the difference between tied and independent advisers (and presumably how this has an impact on the nature of advice given), however, financially unsophisticated consumers tend to be far less aware of the distinction. While consumers generally feel that independent advice is best, the majority of people in the FSA research findings who had not consulted an adviser said that they would consider consulting a bank or building society (ie a tied adviser) if they needed advice. The reasons offered were based on the existing relationship the individual has with the institution, suggesting that familiarity and trust and possibly brand recognition are important factors in choosing an adviser, and not necessarily factors related to the nature and scope of advice provided. It might not be unreasonable to assume that the consumers falling into this category are less financially knowledgeable.

Set against this context, the extent to which consumers can learn from the information-seeking and advice-receiving experience might be questioned. Is it possible for all consumers to acquire knowledge and understanding about financial services from the information and advice received so that they can then use the acquired knowledge in independent decision making in the future? The author 
would argue that the answer is 'no' for the majority of consumers, and that the consumer empowerment often talked about in other contexts is more rhetoric than reality in the context of financial services for this reason. Thus, the proposals put forward by the FSA to alter the structure of the advice industry, and the financial literacy programmes already under way, offer some promise in this direction. Hopefully, in time, a more empowered financial services consumer will be seen, with resultant welfare gains.

Tina Harrison Managing Editor 